\title{
Case Report: Spontaneous Carotid Artery Dissection in an HIV Infected Patient
}

\author{
Carolina Rouanet*, Gustavo Honorio, João Roberto Domingues, Lilian Petroni and Renata Simm \\ Hospital Santa Paula, São Paulo, Brazil
}

Received: 眥: December 14, 2018; Published: 鴊: December 20, 2018

*Corresponding author: Carolina Rouanet, Hospital Santa Paula, São Paulo, Brazil

Abbreviations: CT: Computed Tomography; ICA: Internal Carotid Artery; MRI: Magnetic Resonance Imaging; VZV: Varicella Zoster Virus; HSV:

Herpex Simple Virus; CSF: Cerebro Spinal Fluid

\section{Case Report}

A 39 year-old black man presented to the emergency department reporting a self-limited episode of left hemiparesis [1]. During medical evaluation, a new episode lasting ten minutes with full spontaneous recovery happened. He denied neck pain or recent trauma. In the past medical history, he was HIV positive in regular treatment with Tenofovir, Lamivudine and Efavirenz. His last viral load was undetectable and his CD4 lymphocyte percentage count was 887 [2]. He was started on aspirine and admitted for investigation. His brain computed tomography (CT) scan was normal. On neck and brain CT angiography, there was progressive narrowing in right cervical internal carotid artery (ICA) with complete occlusion in its supraclinoid portion [3]. Brain magnetic

resonance imaging (MRI) revealed multiple areas of restricted diffusion in right carotid artery territory. The MRI angiography revealed no flow in right ICA and its branches, with an intramural hematoma. There were no aneurysms (Figure 1) [4]. Laboratory tests including coagulation profile, screening for auto antibodies, syphilis, hepatitis, Varicella Zoster virus (VZV) and Herpex Simple virus (HSV) serologies were all negative. Cerebrospinal fluid (CSF) analysis was also unremarkable, including research for VZV, HSV 1 and 2, toxoplasmosis, cytomegalovirus and syphilis. CSF fungal, bacterial and micobacterial cultures were negative [5]. The final diagnosis was ischemic stroke due to carotid artery dissection. Anticoagulation was started, without stroke recurrence until out knowledge.

Figure 1:

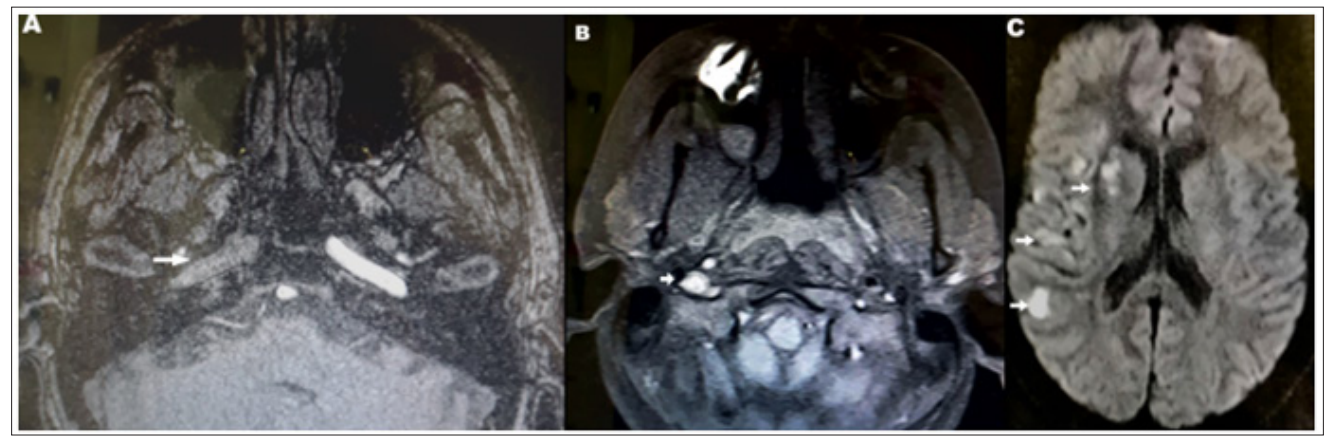

A. Magnetic Ressonance Angiopraphy with no flow in right internal carotid artery.

B. Magnetic Ressonance Imaging (T1 fat supression sequence) showing an intramural right carotid artery hematoma.

C. Magnetic Ressonance Imaging (DWI sequence) with multiple images of restricted diffusion in the right carotid artery territory. 


\section{Discussion}

Ischemic stroke is an important complication of HIV infection. Recently it has been proposed a new ischemic stroke classification $\mathrm{f}$ or HIV patients that includes opportunistic infections, emboli from a cardiac source, accelerated atherosclerotic and non atherosclerotic vasculopathies, vasculitis, small vessel disease, coagulopathies and others. Arterial dissection is responsible for $25 \%$ of strokes in young patients. As risk factors, trauma, connective tissue disorders (probably even intermediate phenotypes not yet recognized), increased homocysteine and recent infections are well established. It is possible that the pro inflammatory state related to the HIV infection played a role in this case, although we cannot identify the exact mechanism that led to the dissection [6]. Current criteria for HIV non atherosclerotic vasculopathy are intimal hyperplasia and elastic degeneration in the absence of atherosclerosis and vasculitis, regardless of age/ exposition to risk factors; or extra or intracranial carotid stenosis with luminal thrombus with or without aneurysm + less than 45 years-old + absence of classic atherosclerotic risk factors.

\section{Conclusion}

It is possible that spontaneous arterial dissection in HIV positive patients is part of the spectrum of HIV non atherosclerotic

ISSN: 2574-1241

DOI: 10.26717/BJSTR.2018.12.002252

Carolina Rouanet. Biomed J Sci \& Tech Res

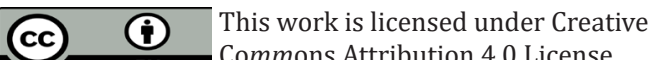

Submission Link: https://biomedres.us/submit-manuscript.php vasculopathy. One must remember those conditions, mainly in the young, without classic stroke risk factors.

\section{References}

1. LA Benjamin, A Bryer, S Lucas, Alan Stanley, Theresa J Allain et al. (2016) Arterial ischemic stroke in HIV. Neurol Neurommunol Neuroinflamm 3: e254.

2. AC Felicio, GS Silva, WAC Santos, Pieri A, Gabbai AA et al. (2006) Spontaneous artery dissection in a patient with human immunodeficiency vírus (HIV) infection. Arq Neuropsiquiatr 64(2-A): 306-308.

3. A Silva Pinto, A Costa, A Sarmenta, Serrão R, Abreu P et al. (2016) Ischemic stroke in HIV-infected patients: a case control study. HIV medicine 18(3): 214-219.

4. G Ortiz, S Koch, JG Romano, Forteza AM, Rabinstein AA (2007) Mechanisms of ischemic stroke in HIV-infected patients. Neurology 68(16): 1257-1261.

5. O Camilo, LB Goldstein (2005) Non-atherosclerotic vascular disease in the Young. Journal of thrombosis and thrombolysis 20(2): 93-103.

6. Adams HP Jr, Bendixen BH, Kappelle LJ, Biller J, Love BB et al. (1993) Classification of subtype of acute ischemic stroke: definitions for use in a multicenter clinical trial. TOAST. Trial of Org 10172 in Acute Stroke Treatment. Stroke 24: 35-41.

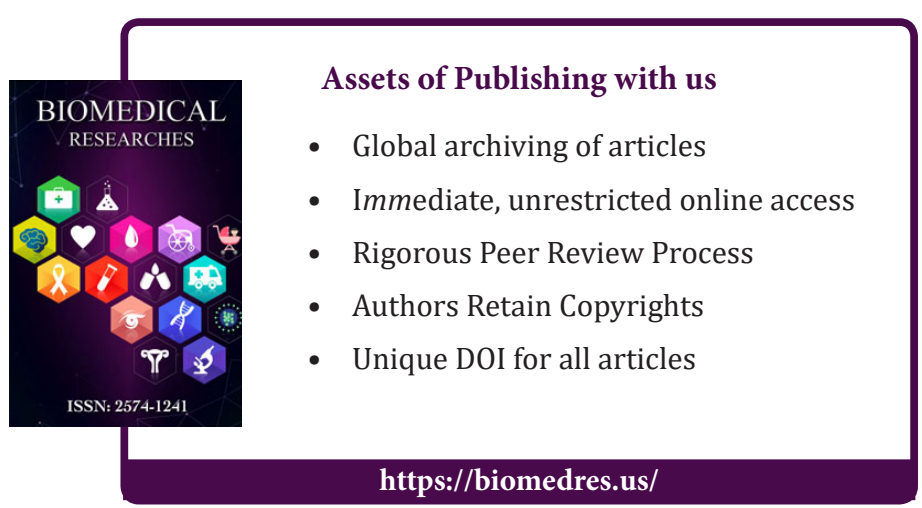

